\title{
LA CONFIGURACIÓN DEL ENTRAMADO INTERGUBERNAMENTAL EN EL CASO URUGUAYO A PARTIR DE LA CREACIÓN DE LOS MUNICIPIOS COMO NUEVO NIVEL DE GOBIERNO
}

\author{
Martín Freigedo* \\ José Raúl Rodríguez** \\ Diego Lamas***
}

\begin{abstract}
RESUMEN. Uruguay ha sido históricamente un país fuertemente centralizado, sin embargo, desde el año 2009, ha iniciado un proceso de reforma descentralizadora con aprobación de las leyes de Descentralización y Participación Ciudadana, que instauraron los municipios como tercer nivel de gobierno, dando la posibilidad a los ciudadanos de elegir autoridades a nivel local. Esta reforma cambió la dinámica de relacionamiento intergubernamental de manera significativa, creando un nuevo tejido de relaciones económicas, jurídicas, políticas y administrativas entre el nivel central, el departamental, y el ahora novel nivel municipal. Este trabajo tiene como objetivo analizar cómo esta configuración se ha desarrollado, caracterizando y describiendo los ámbitos formales de relacionamiento intergubernamental. En tal sentido, si bien los espacios formales han avanzado, todavía se encuentran en un proceso de maduración, que plantea una serie de desafios y riesgos importantes, primando aún ciertas lógicas informales que ponen en amenaza algunos principios cardinales de la reforma descentralizadora.
\end{abstract}

PALABRAS CLAVES. Descentralización territorial. Relaciones intergubernamentales. Uruguay.

\footnotetext{
* Doctor en Ciencias Sociales, FLACSO, México. Maestro en Políticas Públicas, UAM-México. Docente e investigador del Instituto de Ciencia Política, UDELAR. Miembro activo del Sistema Nacional de Investigadores, Nivel I. Mail: martin.freigedo@cienciassociales.edu.uy.

** Candidato a Doctor en Ciencia Política, UDELAR. Maestro en Ciencia Política, UDELAR. Consultor del Programa Uruguay Integra de la Oficina de Planeamiento y Presupuesto. Mail: joseraul.rodriguez.pinho@gmail.com.

*** Doctor en Derecho y Ciencias Sociales por la Universidad de la República, Aspirante a Profesor Adscripto de Derecho Administrativo en la Universidad de la República. Asesor Legal en la Institución Nacional de Derechos Humanos y Defensoría del Pueblo. Mail: dlamas@inddhh.gub.uy.
} 


\begin{abstract}
Uruguay has historically been a strongly centralized country. However, since 2009, a decentralization reform process began with the approval of the laws of Decentralization and Citizen Participation, which established the municipalities as the third level of government, enabling citizens to choose authorities at the local level. This reform significantly modified the dynamics of inter-governmental relations, creating a new weave of economic, legal, political and administrative relations at central and local government level, and further at the new municipal level. This paper aims to analyze how this configuration has been developed, characterizing and describing the formal areas of inter-governmental relations. In this sense, although formal spaces have advanced, they are still in a process that presents important challenges and risks, with informal logics that threaten some cardinal principles of decentralization reform.
\end{abstract}

KEY WORDS. Decentralization. Inter-governmental relations. Uruguay.

\title{
1. INTRODUCCIÓN
}

Pese a ser un país que se ha caracterizado por un alto grado de centralismo y una relativa estabilidad en sus relaciones intergubernamentales (RIGs), en donde los actores sub nacionales han tenido un peso limitado en la gestión de las políticas públicas, en los últimos años es posible identificar dos períodos de reformas que han impactado en las lógicas de acción intergubernamentales y que tuvieron como objetivo dotar de mayor autonomía a las unidades subnacionales a la hora de la gestión de las políticas públicas.

El primer período refiere a la reforma constitucional de 1996, que creó espacios institucionales-formales de relacionamiento verticales y horizontales ${ }^{1}$, que modificaron la lógica de relacionamiento entre el Gobierno Nacional y los Gobiernos Departamentales.

El segundo período se vincula con la implementación de una nueva concepción descentralizadora a partir del año 2005, donde la lógica de gestión de políticas desde una perspectiva territorial ha ocupado un importante lugar en la agenda. Se pueden destacar diversas modificaciones, pero la más relevante para entender las RIGs es la referida aprobación en el año 2009 de la Ley N 18.567 y su posterior modificación en el año 2014, a través de la Ley N ${ }^{\circ}$ 19.272 "Ley de Descentralización política y Participación Ciudadana" (LDyPC).

Estas normas instauraron definitivamente los Municipios como tercer nivel de gobierno, en un país que hasta ese momento solo contaba con gobiernos del nivel central y el nivel departamental (también llamado de segundo nivel). De todas formas, también se han creado normativas muy significativas para entender las lógicas de las transferencias del nivel central al nivel departamental y también al nuevo nivel municipal.

Por último, es posible también identificar una cantidad significativa de espacios de coordinación interinstitucionales que se han creado desde lógicas sectoriales, con una activa participación de los gobiernos subnacionales.

${ }^{1}$ Específicamente a través de la Comisión Sectorial de Descentralización y la institucionalización del Congreso de Intendentes. 
Por tanto, la realidad muestra que el país ha modificado las lógicas de relacionamiento intergubernamental. Sin embargo, no existe un análisis sistemático de estas modificaciones. Este trabajo intenta responder a una pregunta básica: ¿Cómo son las características del entramado de RIGs entre los niveles de gobierno en Uruguay? En virtud de ello, este artículo tiene como objetivo general el mapeo de las RIGs, describiendo los espacios formales de interacción. Por otro lado, se considerarán algunos aspectos centrales del entramado político-institucional del caso uruguayo para entender el funcionamiento de las lógicas formales.

Para esto, en primer lugar, se deben describir las reformas institucionales tendientes a profundizar la descentralización de los gobiernos subnacionales que se han desarrollado en los últimos años. Esta descripción enmarca la discusión sobre las RIGs que se establecen entre los diferentes niveles de gobierno. El segundo apartado aporta algunos elementos analíticos para caracterizar estas relaciones, que se profundizan en el tercer apartado, destinado a describir el mapa de RIGs formales. Por último, el cuarto apartado, discutiremos algunos desafíos para profundizar dichos canales, advirtiendo sobre ciertos factores político-institucionales que están condicionado la eficiencia de los mismos.

\section{LAS REFORMAS INSTITUCIONALES EN URUGUAY.}

Antes de describir la estructura de las RIGs, es necesario establecer claramente los cambios que se han dado en la configuración institucional de las unidades subnacionales. En este sentido, una primera característica del caso es que Uruguay es un país unitario, pero también altamente centralizado. De igual forma y, sobre todo a partir de los últimos gobiernos, los planteamientos sobre la descentralización han estado nuevamente en la agenda. Como se mencionó en la introducción, son diversas las acciones en este sentido, pero la creación de los Municipios como nuevo nivel de gobierno, es sin dudas el cambio políticoinstitucional que debemos considerar como el más relevante en ese sentido.

Previo a la existencia de los Municipios, los Gobiernos Departamentales han sido los únicos gobiernos reconocidos a nivel subnacional. Como sabemos, estos últimos están integrados por dos sistemas orgánicos de existencia necesaria, por un lado, la Intendencia, con funciones esencialmente ejecutivas y, por otro, la Junta Departamental, con funciones de tipo legislativo. La mayoría de los cometidos y atribuciones de estos sistemas se encuentran establecidas en la Constitución de la República y en la Ley Orgánica Municipal (Ley $\mathrm{N}^{\circ}$ 9.515), del año 1935.

A nivel de los Gobiernos Departamentales, la creación de los Municipios hizo que, en la práctica, los primeros deban desarrollar cada vez más funciones típicas de los niveles intermedios de gobierno. En este sentido se ha observado una tendencia creciente a la asunción de cometidos no tradicionales, principalmente en las áreas de políticas sociales, desarrollo económico, ordenamiento territorial y medioambiente, por citar las más comunes, sin que ello haya supuesto una modificación normativa (Rodríguez 2014). Estos cambios se han producido con distinta intensidad y a distintas velocidades en los 19 departamentos. Una tendencia observada a partir de 2005 es el incremento sostenido de las transferencias del gobierno nacional hacia las intendencias, que en parte responden a esta necesidad creciente de asumir nuevas actividades (Freigedo y Rodríguez 2019). 
Por su parte, los Municipios se han insertado en el entramado institucional existente como unidades de gobierno de reciente creación, en el marco de una transformación que presenta una serie de carencias e incertidumbres y como parte de un proceso más amplio de reforma de Estado. Más allá de las particularidades de la discusión sobre la aprobación de la Ley de Descentralización Política y Participación Ciudadana, el resultado fue la creación de 89 municipios en el 2009, ampliados a 112 en el 2014 (Freigedo et al, 2016).

$\mathrm{Al}$ analizar estos nuevos gobiernos desde las diferentes perspectivas de la descentralización territorial, este proceso se enmarca en un proceso fundamentalmente político, en el sentido de que las autoridades de los Municipios (un Alcalde y cuatro Concejales) son electos a través del voto directo por parte de los ciudadanos y, por tanto, este nuevo gobierno cuenta con una importante legitimidad desde lo político. Sin embargo, cuando se analiza el fenómeno desde los puntos de vista jurídico, de gestión y fiscal, la autonomía de los Municipios se reduce sensiblemente.

En relación con la autonomía desde el plano jurídico, debemos considerar en primer lugar el relativamente acotado margen de atribuciones y competencias que prevé actualmente la ley para los Municipios. En segundo lugar y habiéndose definido a los Municipios como órganos desconcentrados de la Intendencia, debe tenerse presente que sus resoluciones serán revisables por razones de legalidad y mérito frente a la presentación de recursos administrativos, razón por la cual debemos reconocer que su autonomía también se encuentra fuertemente acotada en ese sentido.

Vale igualmente tener presente que durante el proceso desde la aprobación de la Ley $\mathrm{N}^{\circ}$ 18.567 hasta la fecha, el legislador no ha tenido una postura unívoca sobre la posición institucional de los Municipios dentro de la estructura orgánica del Gobierno Departamental (Fariña y Oviedo 2017), alternándose una situación de desconcentración, con una suerte de descentralización funcional dentro de la descentralización territorial. ${ }^{2}$

De igual manera, resulta destacable que los municipios tampoco poseen potestad de mando funcional, siendo que sus funcionarios pertenecen en general a la Intendencia y; además no se los reconoce como ordenadores primarios del gasto, siendo un caso de “ordenadores especiales”, según fuera reconocido por el Tribunal de Cuentas ${ }^{3}$.

En cuanto a las actividades de gestión y administrativas, los Municipios poseen bajas atribuciones y potestades propias, en el sentido de que no cuentan con fuertes áreas de gestión con potestad exclusiva y, en línea con lo anterior, estando supeditados a la jerarquía del intendente departamental. Por tanto, esto implica un proceso de negociación constante con los Gobiernos Departamentales, aunque como se verá más adelante, dicho proceso no está regulado normativamente en la legislación, sino que cada caso dependerá de factores

\footnotetext{
${ }^{2}$ En ese sentido, si bien en la primera y última previsión legislativa afirmó la posición de órganos desconcentrados de la Intendencia, durante la vigencia del original artículo 17 de la Ley $\mathrm{N}^{\circ} 19.272$ (y hasta la aprobación de la Ley $\mathrm{N}^{0}$ 19.355) se instauró un régimen bastante particular en el cual solamente eran pasible de recursos ante la Intendencia las cuestiones de legalidad (mediante el recurso de anulación que en una forma errónea refería al artículo 317 de la Constitución), quedando fuera de la posibilidad de revisión por mérito. En función de ello, durante dicho período la posición de la desconcentración de los municipios se encontraba claramente desnaturalizada, asemejándose más a una situación de descentralización jurídica

${ }^{3}$ Por ejemplo, Resolución del Tribunal de Cuentas de fecha 10 de noviembre de 2016, expediente $N^{\circ}$ 2016-17-1-0006863
} 
coyunturales y mayormente informales, que determinarán el tipo de relacionamiento entre ambos niveles de gobierno.

Finalmente, en relación con la descentralización fiscal, los gobiernos municipales dependen en su totalidad de las transferencias de los otros dos niveles, ya que no tienen capacidad de recaudación propia. Estos recursos provienen en su estructura formal del Fondo de Incentivo a la Gestión Municipal (FIGM) y de los recursos que los Gobiernos Departamentales establezcan en los presupuestos respectivos -en el próximo capítulo se profundizará sobre este instrumento-.

Todos estos factores institucionales hacen que los municipios uruguayos posean una más elevada autonomía política que jurídica, de gestión y fiscal, siendo estas últimas muy bajas o en algunos casos prácticamente inexistentes.

\section{APROXIMACIÓN AL ESTUDIO DE LAS RELACIONES INTERGUBERNAMENTALES EN PROCESOS DE DESCENTRALIZACIÓN}

¿Cómo se reequilibra el estado en un proceso de descentralización y qué vías de coordinación y colaboración se establecen entre los niveles de gobierno? La descentralización política y la creación de los Municipios se llevan a cabo en Uruguay en el marco de un proceso más amplio de reforma del estado de orientación neo-desarrollista, donde el estado busca recuperar su primacía en las relaciones con el mercado y la sociedad civil. Sin embargo, los procesos de descentralización no siempre favorecen la eficacia y eficiencia de las políticas públicas, ni necesariamente aseguran un mayor desarrollo económico y social (Carrión 2001, Montecinos 2005), aunque deberían contribuir a la cohesión social y evitar la fragmentación territorial (Jordana 2001). En este marco, caracterizar la naturaleza formal del estado, sus reglas de representación, los sistemas de partidos y las unidades territoriales que forman parte de la totalidad del entramado institucional del estado se torna clave para enmarcar y comprender el funcionamiento de las RIGs.

Existen -según Jordana- tres modalidades que puede asumir el proceso de descentralización: i) el monopolio institucional, donde el estado a través del gobierno central conserva para sí en exclusividad la responsabilidad y la provisión de la política pública; ii) el monopolio distribuido en que el estado trasfiere hacia las unidades subnacionales en régimen de exclusividad la responsabilidad, atribución y competencias; y iii) el pluralismo institucional, que implica un proceso concurrente y coordinado de responsabilidad por el diseño e implementación de una política, función o servicio, entre los niveles de gobierno y aún con participación de terceros (sector privado o púbico no estatal, sociedad civil, etc.). El pluralismo institucional conduce a la necesidad de establecer mecanismos de coordinación que suponen un reequilibrio entre la Administración Central y las unidades subnacionales. Estas lógicas de relacionamiento intergubernamental pueden variar según su intensidad, formalidad y colaboración. ¿Cuáles son las lógicas de ese relacionamiento? Jordana establece tres vías o lógicas: 1) Coordinación formal; 2) Coordinación informal; y 3) las llamadas "redes gubernamentales" entre comunidades profesionales (Jordana 2001).

“...Por relaciones formalizadas se entienden los procedimientos de asignación, coordinación y decisión de carácter institucional, centrados en temas sustantivos, de reparto de poderes sobre políticas sectoriales y áreas de gestión entre distintos niveles de 
gobierno, o bien relativos a la distribución de recursos financieros y responsabilidades fiscales...”(Jordana 2001). Por ejemplo, son lógicas formales las que establecen mecanismos de asignación de recursos en base a impuestos, préstamos y transferencias, con criterios de compensación territorial y donde las reglas están claramente establecidas y existe capacidad para implementarlas. Al contrario, las lógicas informales no suelen ser transparentes, muchas veces son ad hoc, y se dan a través de los partidos sin que prime un criterio de ecuanimidad o compensación territorial establecido por normas y reglas claras. Finalmente, las redes gubernamentales entre comunidades profesionales se dan entre políticos, técnicos y burócratas que trabajan en el gobierno y van generando un saber hacer basado en la confianza recíproca.

Estas tres lógicas de RIGs funcionan como tipos ideales; en la realidad se presentan entremezcladas. Asimismo, es necesario que las normas formales se complementen con normas informales que aseguren la confianza en dichas relaciones: “. . La existencia de una cultura político-institucional muy homogénea entre los responsables públicos constituye un elemento de gran importancia para facilitar la cooperación entre los actores..." (Jordana 2001).

A los efectos de observar y caracterizar las RIGs en el caso concreto, resulta necesario observar los procedimientos efectivos de toma de decisiones. ¿Existe imposición de una de las partes, permanente o coyuntural, o se establece un margen para la negociación? ¿Cuáles son las capacidades y recursos claves asociados a las relaciones de poder (recursos políticos e institucionales, transferencias)? ¿Cómo se establecen los sistemas de control y de resolución de conflictos (por medios políticos o a través de tribunales o ámbitos especializados)? (Ver cuadro 1).

Cuadro 1. Dimensiones de análisis de las RIGs formalizadas

\begin{tabular}{|l|l|}
\hline Dimensiones de análisis & $\begin{array}{l}\text { Relaciones intergubernamentales } \\
\text { formalizadas }\end{array}$ \\
\hline $\begin{array}{l}\text { Procedimientos de asignación } \\
\text { decompetencias }\end{array}$ & $\begin{array}{l}\text { Basados en normas transparentes y } \\
\text { aceptadas }\end{array}$ \\
\hline Mecanismos de coordinación & $\begin{array}{l}\text { Ámbitos sectoriales formalmente establecidos } \\
\text { con capacidad de toma de decisiones }\end{array}$ \\
\hline Resolución de conflictos & $\begin{array}{l}\text { Existen ámbitos institucionalizados, } \\
\text { neutrales, con capacidad de resolución (Poder } \\
\text { Judicial, tribunales especializados, otros) }\end{array}$ \\
\hline Régimen de distribución de recursos & $\begin{array}{l}\text { Orientados por objetivos de compensación } \\
\text { territorial }\end{array}$ \\
\hline $\begin{array}{l}\text { Mecanismos de financiación y } \\
\text { asignación de recursos fiscales }\end{array}$ & $\begin{array}{l}\text { Transparentes, eficientes, basados en normas } \\
\text { reconocidas y aceptadas }\end{array}$ \\
\hline
\end{tabular}

Fuente: elaboración propia en base a Jordana 2001. 


\section{4. Ámbitos formales de relaciones intergubernamentales multinivel.}

Entender las RIGs en Uruguay implica precisar y describir una serie de dispositivos de naturaleza y características diferentes. Este apartado está destinado a describir brevemente estos dispositivos, con el objetivo de establecer una primera aproximación que permita demarcar el mapa de espacios de RIGs formales que se presentan. El siguiente cuadro resume los espacios identificados.

Cuadro 2. Principales reglas y ámbitos formalizados de relacionamiento intergubernamental en Uruguay

\begin{tabular}{|c|c|c|c|}
\hline Niveles & Normas y ámbitos & Actores & Dimensiones \\
\hline \multirow{8}{*}{$\begin{array}{c}\text { Nacional } \\
- \\
\text { Departamental }\end{array}$} & $\begin{array}{l}\text { Comisión sectorial de } \\
\text { descentralización }\end{array}$ & $\begin{array}{l}\text { OPP, ministerios, } \\
\text { intendentes }\end{array}$ & $\begin{array}{l}\text { Mecanismos } \\
\text { de coordinación }\end{array}$ \\
\hline & $\begin{array}{l}\text { Comisión Especial de } \\
\text { Asuntos Municipales - } \\
\text { Poder Legislativo, } \\
\text { Cámara de } \\
\text { Representantes. }\end{array}$ & $\begin{array}{l}\text { Representantes } \\
\text { Nacionales }\end{array}$ & $\begin{array}{l}\text { Procedimientos } \\
\text { de asignación } \\
\text { de } \\
\text { competencias }\end{array}$ \\
\hline & $\begin{array}{l}\text { Constitución de formas } \\
\text { asociativas, personas } \\
\text { jurídicas y fideicomisos } \\
\text { por GDs }\end{array}$ & $\begin{array}{l}\text { Intendencias, } \\
\text { Ministerios, Entes } \\
\text { Autónomos y Servicios } \\
\text { Descentralizados }\end{array}$ & $\begin{array}{l}\text { Mecanismos } \\
\text { de coordinación }\end{array}$ \\
\hline & Agenda Metropolitana & $\begin{array}{l}\text { Presidencia de la } \\
\text { República, IM, IC, ISJ }\end{array}$ & $\begin{array}{l}\text { Mecanismos } \\
\text { de coordinación }\end{array}$ \\
\hline & $\begin{array}{l}\text { Espacios de coordinación } \\
\text { sectoriales y programas }\end{array}$ & $\begin{array}{l}\text { Intendencias, } \\
\text { Ministerios }\end{array}$ & $\begin{array}{l}\text { Mecanismos de } \\
\text { coordinación }\end{array}$ \\
\hline & $\begin{array}{l}\text { Lesión de autonomía (Art. } \\
283 \text { de la Constitución de } \\
\text { la República) }\end{array}$ & Poder Judicial, GDs & $\begin{array}{l}\text { Resolución de } \\
\text { conflictos }\end{array}$ \\
\hline & SUCIVE & $\begin{array}{l}\text { Presidencia de la } \\
\text { República, CI }\end{array}$ & $\begin{array}{l}\text { Régimen de } \\
\text { distribución de } \\
\text { recursos }\end{array}$ \\
\hline & $\begin{array}{l}\text { Régimen de } \\
\text { transferencias nacionales } \\
\text { (Art. 214, } 230 \text { y } 298 \text { de la } \\
\text { Constitución de la } \\
\text { República) } \\
\text { Leyes de Presupuesto } \\
\text { Quinquenal }\end{array}$ & $\begin{array}{l}\text { Presidencia de la } \\
\text { República, MEF, Poder } \\
\text { Legislativo }\end{array}$ & $\begin{array}{l}\text { Régimen de } \\
\text { distribución de } \\
\text { recursos }\end{array}$ \\
\hline \multirow{3}{*}{$\begin{array}{l}\text { Departamental - } \\
\text { Departamental }\end{array}$} & CI & Intendentes & $\begin{array}{l}\text { Mecanismos de } \\
\text { coordinación }\end{array}$ \\
\hline & Congresos de Ediles & $\begin{array}{l}\text { Ediles } \\
\text { departamentales }\end{array}$ & $\begin{array}{l}\text { Mecanismos } \\
\text { de coordinación }\end{array}$ \\
\hline & $\begin{array}{l}\text { Acuerdos } \\
\text { interdepartamentales }\end{array}$ & $\begin{array}{l}\text { Intendentes, Juntas } \\
\text { Departamentales }\end{array}$ & $\begin{array}{l}\text { Mecanismos } \\
\text { de coordinación }\end{array}$ \\
\hline
\end{tabular}




\begin{tabular}{|c|c|c|c|}
\hline Niveles & Normas y ámbitos & Actores & Dimensiones \\
\hline \multirow[t]{2}{*}{$\begin{array}{l}\text { Nacional - } \\
\text { Municipal }\end{array}$} & $\begin{array}{l}\text { Fondo de Incentivos a la } \\
\text { Gestión Municipal (FIGM) }\end{array}$ & $\begin{array}{l}\text { OPP, intendencias, } \\
\text { municipios (Alcaldes, } \\
\text { concejales) }\end{array}$ & $\begin{array}{l}\text { Régimen de } \\
\text { distribución de } \\
\text { recursos }\end{array}$ \\
\hline & Programas sectoriales & $\begin{array}{l}\text { OPP, ministerios, } \\
\text { intendencias, municipios }\end{array}$ & $\begin{array}{l}\text { Mecanismos de } \\
\text { coordinación }\end{array}$ \\
\hline $\begin{array}{l}\text { Departamental } \\
\text { - Municipal }\end{array}$ & $\begin{array}{l}\text { Mecanismos de } \\
\text { coordinación } A d h o c\end{array}$ & $\begin{array}{l}\text { Intendente, Junta } \\
\text { Departamental (ediles), } \\
\text { municipios (Alcalde, } \\
\text { concejales) }\end{array}$ & $\begin{array}{l}\text { Mecanismos de } \\
\text { coordinación }\end{array}$ \\
\hline \multirow{2}{*}{$\begin{array}{l}\text { Municipal- } \\
\text { Municipal }\end{array}$} & Plenario de municipios & OPP,CI, Municipios & $\begin{array}{l}\text { Mecanismos de } \\
\text { coordinación }\end{array}$ \\
\hline & $\begin{array}{l}\text { Redes de municipios y } \\
\text { acuerdos } \\
\text { intermunicipales }\end{array}$ & $\begin{array}{l}\text { Ministerios, } \\
\text { intendentes, alcaldes, } \\
\text { concejales }\end{array}$ & $\begin{array}{l}\text { Mecanismos } \\
\text { de } \\
\text { coordinación }\end{array}$ \\
\hline
\end{tabular}

Fuente: elaboración propia.

\subsection{Normas y ámbitos del nivel nacional-departamental.}

Dentro de los espacios formales de RIGs entre el nivel nacional y departamental, es posible identificar una variedad importante de canales. Sin embargo, no todos tienen la misma relevancia a la hora de entender el impacto en la distribución de competencias.

\section{- Comisión Sectorial de Descentralización (CSD)}

Desde el punto de vista de las RIGs, la creación institucional más relevante de la reforma constitucional de 1996 fue la puesta en marcha de la Comisión Sectorial de Descentralización. Según el artículo 230 de la Constitución de la República, dicha comisión "estará exclusivamente integrada por delegados del Congreso de Intendentes y de los Ministerios competentes, la que propondrá planes de descentralización que, previa aprobación por el Poder Ejecutivo, se aplicarán por los organismos que corresponda".

Este espacio de coordinación interpartidaria e interinstitucional, tiene como cometido llevar adelante la agenda de discusión sobre el proceso de descentralización en el país desde los órganos ejecutivos. Esta agenda es abierta y coyuntural de acuerdo con las realidades políticas del momento, sin embargo, tiene algunas atribuciones específicas a la hora de asignar recursos. Sobre todo, los referidos al Fondo de Desarrollo del Interior (FDI), dado que la CSD es la que regula dichos fondos y aprueba los proyectos presentados por los Gobiernos Departamentales. En las próximas páginas, cuando se discuta particularmente la estructura de transferencias, se profundizará sobre dicho fondo.

\section{- Comisión de Asuntos Municipales del Parlamento}

Las comisiones parlamentarias cumplen un rol relevante a la hora de elaborar políticas por medio de la enmienda de proyectos (Guedess, 2017). Estas comisiones se tornan en espacios donde se busca la especialización sobre algunos asuntos, y están integradas por representantes estables de los diferentes partidos políticos con representación parlamenta- 
ria, con el objetivo de favorecer la coordinación de las unidades partidarias y dar cierto orden a la negociación legislativa. Según Cashquetti (2008:251):

[l]a organización del trabajo legislativo en comisiones especializadas, con prerrogativas específicas y jurisdicciones delimitadas, supone una estructura estable que favorece los compromisos creíbles a través del tiempo.

En este marco, se ha creado una comisión especial denominada de "Asuntos Municipales" que ha jugado un rol determinante para llevar adelante los procesos de reforma institucional, dado que en el seno de esta comisión se discutió el proyecto de Ley de Descentralización Política y Participación Ciudadana. Allí se ha planteado el ámbito de discusión de los diferentes proyectos presentados, y oportunamente se llegó a un acuerdo inter partidario sobre la ley final aprobada por mayorías especiales, y también las modificaciones posteriores.

- Régimen de transferencias del nivel central hacia los Gobiernos Departamentales

La estructura de transferencias hacia los Gobiernos Departamentales está compuesta por dos grandes normativas que diferencia entre transferencias condicionadas e incondicionadas. En cuanto a las transferencias no condicionadas, el principal aporte surge del literal C) del artículo 214 de la Constitución de la República. Este artículo establece que el Presupuesto Nacional se aprobará y se estructurará tomando en cuenta: "Los recursos y la estimación de su producido, así como el porcentaje que, sobre el monto total de recursos, corresponderá a los Gobiernos Departamentales".

Esta previsión constitucional determina que el Gobierno Nacional debe contemplar dentro de su presupuesto las trasferencias a los Gobiernos Departamentales, sin embargo, no establece de manera clara cómo se estructuran dichas transferencias. Durante los últimos tres periodos de gobierno el criterio ha sido recurrente, ya que a la hora de aprobar el presupuesto nacional se ha establecido que se le otorgará a los Gobiernos Departamentales un total del 3,3\% del total de los recursos del presupuesto nacional. ${ }^{4}$

Luego de ciertas deducciones, los recursos se distribuyen entre los dieciocho Departamentos restantes, por medio de una fórmula que toma en cuenta la población, la pobreza y la extensión territorial.

Un punto al que se debe hacer mención es que esta estructura de transferencias incondicionadas del presupuesto nacional se realizó recién a partir del período 2006-2010 y se ha repetido para los dos períodos de gobierno subsiguientes. Sin embargo, vale tener presente que el funcionamiento de las transferencias antes se daba por medio de partidas diferentes en cuanto al monto y al tiempo en que se otorgaban de acuerdo con criterios discrecionales de los gobiernos de turno. Esto ha tenido importantes problemas a la hora de la gestión, ya que no permitía a los Gobiernos Departamentales tener claro el monto total que se iba a transferir y así poder planificar el quinquenio, pero a su vez podía ser utilizado como un mecanismo de control político desde el centro a la periferia.

${ }^{4}$ El monto total de transferencias, está sujeto posteriormente a un conjunto de deducciones que tienen que ver con un porcentaje del total que se destina al Gobierno Departamental de Montevideo, el total de recursos ejecutados en los Gobiernos Departamentales del interior por el Programa de Mantenimiento de Caminería Rural, y los recursos ejecutados por el Programa de Desarrollo y Gestión Municipal a cargo de la Oficina de Planeamiento y Presupuesto (OPP). 
En este sentido, cuando las transferencias están basadas en fórmulas polinómicas o en un porcentaje del origen de la recaudación, se producen mayores incentivos para la estabilidad. Ya que esto genera mayor previsión para los gobiernos subnacionales y mayores incentivos para coordinar con el nivel central (Jordana 2001). Por tanto, la lógica de interacción para la distribución de los recursos que se ha generado en los últimos períodos de gobiernos ha llevado a que exista una mayor estabilidad en el relacionamiento entre el nivel central y el subnacional.

En promedio, la suma de todas estas transferencias representa un $28 \%$ del total, por lo que las incondicionadas representan un 72\%, según datos del año 2017 (fuente: OTUOPP). En el año 2016 estos porcentajes eran de 21,2\% para las transferencias condicionadas y las 79\% de las incondicionadas (fuente: OTU-OPP).

La autonomía financiera es un aspecto central cuando se analiza el grado de descentralización que existe, y marca el tipo de RIGs que se establece entre niveles de gobierno. En este sentido, cuanto mayor sean las transferencias, mayor será el grado de dependencia, lo que limita las posibilidades de acción de los niveles inferiores. Si se analiza el caso uruguayo, es posible percibir que ha aumentado significativamente el peso de las transferencias en el total de ingresos de los Gobiernos Departamentales (ver Gráfico 1). Se destaca que el año 1991 es el que presenta el promedio más alto de autosuficiencia, ya que el 84,5\% de los ingresos eran provenientes de la propia recaudación sub nacional. El último dato disponible muestra que en el 2016 los ingresos propios representan el 70,4\%.

\section{- Sistema Único de Cobro Vehicular (SUCIVE)}

Uno de los aspectos que ha generado mayor conflicto entre los Gobiernos Departamentales ha tenido que ver con el sistema del cobro de patentes de rodados, tributo previsto en el numeral 6) del artículo 297 de la Constitución. Dentro de la estructura fiscal de los Gobiernos Departamentales, uno de los tributos más relevantes que pueden cobrar de forma autónoma es la patente de rodados. La norma constitucional referida permite a los Gobiernos Departamentales fijar la alícuota del cobro en base a un criterio discrecional, lo que históricamente ha generado una disparidad significativa entre los tributos que han debido pagar los contribuyentes según el departamento en el que registren el vehículo, generando la conocida guerra de las patentes.

Ante esta situación y luego de un largo proceso de negociación iniciado en el año 2010, finalmente y a través de la Ley $\mathrm{N}^{\circ} 18.860$, de 11 de enero de 2012 , se aprobó la creación del Sistema Único de Cobro de Ingresos Vehiculares (SUCIVE). Esta ley estableció la creación de la Comisión de Seguimiento del Sistema Único de Cobro de Ingresos Vehiculares (SUCIVE), la que se integra por siete miembros: cinco de ellos designados por el Congreso de Intendentes, uno designado por la Oficina de Planeamiento y Presupuesto y otro designado por el Ministerio de Economía y Finanzas.

El fondo generado por SUCIVE se gestiona por medio de un instrumento de fideicomiso, garantizando la distribución de los recursos, en los términos previstos en la ley.

- Constitución de formas asociativas, personas jurídicas y fideicomisos por Gobiernos Departamentales

Otra de las posibilidades de vinculación de Gobiernos Departamentales con ámbitos nacionales (e incluso entre sí), se encuentra contemplada en la Ley $\mathrm{N}^{0} 18.093$, de 8 de enero 
de 2007. Si bien esta norma ha tenido una casi inexistente utilización, plantea un panorama sumamente novedoso en cuanto a la gestión coordinada de entidades departamentales con organismos nacionales.

En particular, el artículo 1 de la ley referida faculta a los Gobiernos Departamentales "a adoptar todas las formas jurídicas necesarias para acordar entre sí, o con el Poder Ejecutivo, entes autónomos o servicios descentralizados, la organización y prestación de servicios y actividades propias y comunes, tanto en sus respectivos territorios como en la forma regional o interdepartamental". La ley autoriza que los acuerdos referidos puedan instrumentarse a través de "empresas públicas o por personas públicas no estatales, creadas por ley nacional”, con directorios que podrán incluso entidades privadas vinculadas a las áreas que constituyen la materia objeto de la gestión.

En definitiva, si bien esta norma no ha tenido casi aplicación, sin duda plantea un marco normativo sumamente interesante para los Gobiernos Departamentales, a los efectos del cumplimiento de actividades enmarcadas en sus cometidos constitucionales y legales, en un marco de coordinación nacional e interdepartamental.

En segundo término, vale tener presente también la posibilidad de coordinación y ejecución de cometidos a través de la instrumentación de fideicomisos públicos con coparticipación como fideicomitentes de Gobiernos Departamentales, conjuntamente con otros o con Entes Autónomos, Servicios Descentralizados u organismos de la Administración Central. ${ }^{5}$

\section{- Agenda Metropolitana}

Con la necesidad de coordinar acciones conjuntas entre los Gobiernos Departamentales que integran el área metropolitana (Montevideo, Canelones y San José) y el gobierno nacional, desde el gobierno central se creó el Programa Agenda Metropolitana (AM) en el año 2005. Este programa se originó desde Presidencia de la República, con el objetivo central de articular y gestionar de manera articulada los territorios que engloba, como "una carta de navegación común, como una forma de compartir problemas y soluciones" (Agenda Metropolitana, 2007: 401). Con relación a su integración, está compuesta por una Junta Directiva integrada por los Intendentes de los tres Gobiernos Departamentales, y un Equipo de Coordinación Ejecutiva, en donde participan delegados de los Intendentes y un coordinador general. En base a este acuerdo, se han llevado adelante algunas iniciativas conjuntas, entre los actores que la componen, pero también con otras instituciones públicas y privadas. Sin embargo, si bien fomenta la acción conjunta no tiene potestades formales y legales autónomas, lo cual implica que en la práctica las acciones que se desarrollen deben ser aprobadas previamente por los Gobiernos Departamentales (Magri et al, 2011).

- Otros ámbitos sectoriales de coordinación

Como se indicó antes, desde hace varios períodos de gobierno la cuestión de la gestión de las políticas territoriales y la importancia de la descentralización ha ocupado un lugar

\footnotetext{
${ }^{5}$ Uno de los ejemplos más llamativos en este punto lo constituye el Fideicomiso para la Administración del Museo del Carnaval, en el que participan los Ministerios de Turismo y Educación y Cultura, la Adm. Nacional de Puertos y la Intendencia de Montevideo, entre otros. Sin perjuicio existen otros numerosos fideicomisos constituidos directamente por Gobiernos Departamentales para la ejecución de cometidos, en general vinculados al desarrollo de obra pública departamental.
} 
relevante en la agenda. Más allá de los esfuerzos por reforzar el segundo nivel de gobierno y la creación del tercer nivel, también desde los ámbitos centrales se ha buscado modificar la lógica de gestión de las políticas públicas que desembocan en el territorio. En este marco se han creado una importante cantidad de espacios de coordinación interinstitucional con el objetivo de implementar políticas a nivel territorial en diferentes arenas de políticas ${ }^{6}$.

En todos estos ámbitos, en mayor o menor medida, existe una presencia de los gobiernos subnacionales (sobre todo del nivel departamental, y en algunos casos también del nivel municipal). No se pretende aquí realizar una evaluación de cada uno de éstos ámbitos, sin embargo, es posible destacar que los mismos son ámbitos que buscan la coordinación y no interfieren de manera directa sobre las atribuciones de los diferentes actores que participan en ellos. Por tanto, no son ámbitos que desde el punto de vista formal puedan incidir en la autonomía de los gobiernos subnacionales.

\section{- Acción por lesión de autonomía}

Otro aspecto para entender las lógicas de las RIGs, pasa por determinar los canales formales de resolución de conflictos, vinculados especialmente con la protección legal de la autonomía de los Gobiernos Departamentales.

En el caso uruguayo, la posibilidad de recurrir a la principal protección está para los Gobiernos Departamentales està definida por la Constitución en su artículo 283, donde se establece que "Los Intendentes o las Juntas Departamentales podrán reclamar ante la Suprema Corte de Justicia por cualquier lesión que se infiera a la autonomía del departamento, en la forma que establezca la ley."

En este sentido y al igual que sucede con otros institutos como la acción de inconstitucionalidad, los Gobiernos Departamentales se encuentra legitimados para recurrir al órgano máximo del Poder Judicial para presentar un accionamiento judicial si consideran que se está vulnerando su autonomía en relación a sus atribuciones o competencias. De hecho, existen varios casos en donde los Intendentes han presentado acciones en virtud de considerar que el Gobierno Nacional vulneró su autonomía.

De todas formas, al análisis de las sentencias de la SCJ ante reclamos presentados por los Gobiernos Departamentales desde 1991 a 2016, y considerando los datos arrojados por la Base de Jurisprudencia Nacional Pública (BJNP) de Poder Judicial, es posible identificar 18 Sentencias en este sentido, lo que da cuenta de la baja recurrencia a este instrumento.

\section{- Recursos de apelación por oportunidad y por inconstitucionalidad o legalidad}

Más allá de los instrumentos de coordinación y protección legal de la autonomía de los Gobiernos Departamentales, existen como contrapartida instrumentos específicos de control respecto a las decisiones adoptadas por los Gobiernos Departamentales.

En este punto abordaremos dos de los procedimientos reconocidos en nuestra Constitución, como lo son el recurso de oportunidad y el recurso de inconstitucionalidad y legalidad.

${ }^{6}$ Entre los que se pueden destacar las Mesas Interinstuticionales de Políticas Sociales (coordinadas por el Ministerio de Desarrollo Social), las Mesas de Desarrollo Rural (coordinadas por el Ministerio de Ganadería, Agricultura y Pesca), los instrumentos de Ordenamiento Territorial (coordinados por el Ministerio de Vivienda, Ordenamiento Territorial y Medio Ambiente), los Comité de Emergencia ante desastres naturales (coordinado por Presidencia de la República), y los Centros MEC (coordinados por el Ministerio de Educación y Cultura). 
Como veremos, en ambos casos, se da la particularidad que los mismos no se dirimen ante órganos con competencia típicamente jurisdiccional, sino que se interponen y resuelven en el ámbito de la Cámara de Representantes.

En tal sentido, el artículo 300 de la Constitución prevé el llamado recurso de apelación por oportunidad, por intermedio del cual se prevé "El Poder Ejecutivo podrá apelar ante la Cámara de Representantes dentro de los quince días de publicados en el Diario Oficial, fundándose en razones de interés general, los decretos de los Gobiernos Departamentales que crean o modifican impuestos..."

Tal como surge de la norma parcialmente transcripta, se trata de un accionamiento que, en un breve plazo de su publicación, puede impulsar exclusivamente el Poder Ejecutivo, basado en razones de interés general y en virtud de cuestiones de legalidad o de mérito. El objeto del recurso son los actos de naturaleza legislativa emitidos por las Juntas Departamentales que crean o modifican impuestos. Tal como puede notarse, este instrumento implica un claro control desde el Gobierno Central a las políticas tributarias fijadas por los Gobiernos Departamentales, considerándose que el fundamento radica el rol de conductor de la economía que posee el Poder Ejecutivo (Delpiazzo, 2009).

Como se indicó al inicio, el ámbito en el cual se dirime este accionamiento es la Cámara de Representantes, la que deberá resolver en un plazo de 60 días respecto al recurso interpuesto, considerándose rechazado el mismo si no se resuelve en el plazo indicado. La presentación del accionamiento tiene efecto suspensivo respecto a la norma recurrida.

En segundo lugar, a través de lo dispuesto en el artículo 303, el constituyente ha regulado el llamado recurso de apelación por inconstitucionalidad o ilegalidad Mediante el mismo, se prevé que tanto los decretos de la Junta Departamental, como las resoluciones del Intendente, contrarios a la Constitución o las leyes -y que no sean impugnables ante el Tribunal de lo Contencioso Administrativo-, son susceptibles de ser apelados mediante un recurso a presentarse ante la Cámara de Representantes. A diferencia del caso anterior, se acota su objeto a la legalidad del acto y en cuanto a la legitimación, se prevé aquí que podrán recurrir un tercio del total de miembros de la Junta Departamental o mil ciudadanos inscriptos en el Departamento.

El procedimiento resulta en grandes rasgos similar al previsto para el artículo 300, con la salvedad que el plazo para su presentación es de 15 días desde la promulgación de la norma sometida a recurso. Los requisitos y formalidades para la presentación y la tramitación del proceso se encuentran regulados en la Ley $\mathrm{N}^{\circ}$ 18.045, de 23 de octubre de 2006, previniéndose que el plazo de resolución es también de 60 días, aunque en este caso la interposición del recurso no tiene efecto suspensivo. En caso que la Cámara de Representantes no se pronuncie en dicho plazo, se considera rechazado el mismo.

\subsection{Normas y ámbitos entre Gobiernos Departamentales.}

\section{- Congreso de Intendentes}

Este espacio de cooperación y coordinación es integrado por todos los ejecutivos departamentales, y tiene una larga tradición en la política uruguaya. Sus orígenes datan ya desde 1943, aunque los mismos tuvieron lugar sin regularidad y principalmente a influjo de Montevideo, siendo que, a partir del año 1983, surge con un funcionamiento administra- 
tivo independiente de las Intendencias, aunque financiado con aportes de éstas (Vázquez, 1997).

En ese sentido, si bien es un órgano que funciona hace más de medio siglo recién con la reforma constitucional de 1996 se ha institucionalizado e integrado entre los órganos de previsión constitucional, tal como se recoge a través en el artículo 262 de la Constitución de la República, por el que se establece que: "Habrá un Congreso de Intendentes, integrado por quienes fueren titulares de ese cargo o lo estuvieren ejerciendo, con el fin de coordinar las politicas de los Gobiernos Departamentales".

Sin perjuicio de lo complejo que resulta su ubicación en la organización del Estado Uruguayo, este cambio en el nivel de institucionalización dio lugar a que el Congreso tomara una mayor relevancia en la vida política nacional, en tanto permitió darle a esta institucionalidad nuevas funciones y atribuciones desde una dimensión formal, incorporando su representación y su voz en una serie de normativas que tiene que ver con la gestión del Estado en el territorio. ${ }^{7}$

En cuanto al funcionamiento interno, el Congreso aprueba su propio Reglamento de Funcionamiento, que se basa en actuación del Plenario integrado por todos los Intendentes Departamentales y las Comisiones (que se integrarán voluntariamente por los Intendentes, y cada una contará con un máximo de 6 miembros).

\section{- Congreso de Ediles}

Así como existe un espacio de interacción entre los Intendentes Departamentales, también existe un espacio de coordinación entre los Ediles que conforman las Juntas Departamentales (órgano legislativo departamental). El Congreso de Ediles es el espacio que reúne a los Ediles de las diecinueve Juntas Departamentales, y funciona a través de una Asamblea General y por Comisiones según temáticas específicas. Ahora bien, a diferencia del Congreso de Intendentes, que como se vio es reconocido formalmente por la Constitución de la República, el Congreso de Ediles no tiene reconocimiento formal y es reconocido como una Asociación Civil sin fines de lucro. Esta consideración determina que, si bien es relevante como espacio de negociación y presión política como colectivo, no tiene potestades formales sobre ningún asunto específico, y por tanto no tiene posibilidad de decidir cómo colectivo sobre cuestiones que afecten directamente la gestión de los gobiernos subnacionales.

\section{- Acuerdos interdepartamentales}

Por otro lado, es dable destacar que también existen acuerdos interdepartamentales concretos sobre ciertos asuntos. Ejemplo de ello son los Planes Regionales de Ordenamiento Territorial, los cuáles plantean áreas comunes que regulan zonas de intervención, las que afectan a dos o más territorios departamentales, tal como sucede en cuencas y/o humedales, entre otros casos.

${ }^{7}$ Por ejemplo, por medio de la integración de la Comisión Sectorial de Descentralización, o también mediante la posibilidad de ser el interlocutor fundamental a la hora de negociar con el gobierno central el régimen de transferencias financieras del nivel central al subnacional (tanto Departamental como Municipal). 


\subsection{Normas y ámbitos entre el nivel central y el nivel municipal}

\section{- Fondo de Incentivos a la Gestión Municipal}

En cuanto al sistema de financiamiento de los municipios, la ley establece que los mismos no pueden fijar ni recaudar impuestos de base local proviniendo sus recursos del Fondo de Incentivo a la Gestión Municipal (FIGM), que surge del presupuesto nacional y es administrado por la OPP, así como de las partidas que le asigne el respectivo Gobierno Departamental. Vale tener presente que el FIGM se distribuye entre los distintos municipios en base a una fórmula polinómica que toma en cuenta población, extensión territorial y nivel de desarrollo humano.

Estos fondos del FIGM no se transfieren directamente a los municipios, sino que se transfieren a los Gobiernos Departamentales y luego éstos a los municipios. Esta situación se genera por la inserción institucional de los municipios, en tanto forman parte de la estructura del sistema orgánico Intendencia, como órganos desconcentrados, por supuesto sin autonomía y personería jurídica independiente, lo que limita en gran medida la posibilidad de recibir recursos de forma directa.

Esta situación da lugar a que también exista un predominio informal en el tipo de relacionamiento intergubernamental a la hora de hacer llegar de forma efectiva los recursos transferidos por el FIGM a los municipios. De todas formas, el sistema prevé algunos instrumentos de planificación anual y compromisos de gestión entre intendencias y municipios tendientes a formalizar esta relación.

- $\quad$ Programas sectoriales

En segundo término, existen en la órbita de la Administración Central una serie de programas y líneas de proyectos que suelen favorecer recursos financieros y técnicos con destino a los municipios.

Muchos de ellos provienen de la cooperación internacional o cuentan con financiamiento externo, mientras que otros forman parte de los recursos presupuestales del gobierno que, sin embargo, se transfieren bajo una lógica extrapresupuestal, es decir, en el marco de llamados o concursos donde los muncipios postulan y acceden en el marco de determinadas reglas.

En este sentido se pueden mencionar el programa REALIZAR del Ministerio de Transporte y Obras Públicas implementado en el período 2010-2015, tendiente a promover proyectos de infraestructura con participación ciudadana en los municipios. Otro ejemplo es el Fondo + Local del Programa Uruguay Integra de la OPP que ofrece financiamiento, acompañamiento técnico y capacitación aplicada a proyectos de iniciativa local en las áreas de espacios públicos, medioambiente, cultura eidentidad.

\subsection{Normas y ámbitos entre nivel departamental y nivel municipal}

De acuerdo a lo dispuesto en la Ley $\mathrm{N}^{\circ} 19.272$, no se encuentra prevista la institucionalización de espacios de interacción donde dirimir conflictos entre los niveles subnacionales de gobierno.

Teniendo presente esta situación y sobre la base de la posición orgánico institucional que ocupan los municipios, se da lugar a que exista una amplia heterogeneidad de formas 
de interacción entre el nivel departamental y municipal. En algunos casos los Gobiernos Departamentales establecieron espacios regulares de coordinación, donde participan el Intendente y parte de su equipo junto a las autoridades municipales, donde se discuten temas de interés y se planifica la gestión en conjunto. En otros casos, la lógica pasa solamente por el contacto informal entre las autoridades municipales y el equipo de gobierno departamental para atender temas puntuales.

En este sentido y dada la posición jerárquica del Intendencia, la lógica de resolución de conflictos lleva a una supremacía del nivel superior sobre el inferior, y los actores municipales quedan supeditados a la voluntad política del Intendente de turno de dar lugar a las demandas del gobierno local, abriendo los espacios necesarios para negociar y coordinar los problemas intergubernamentales.

Por su parte, cuando se analiza la distribución de recursos que provienen desde los Gobiernos Departamentales hacia los Municipios, se debe destacar que también prima una lógica de relacionamiento informal. Las transferencias provenientes del gobierno central a través del FIGM están basadas en reglamentos que establecen claramente los criterios sobre los cuales los municipios acceden al financiamiento, sin embargo, las transferencias que provienen de los gobiernos departamentales no están claramente reguladas, dado que cada GD puede fijar la distribución de sus recursos autónomamente.

Este escenario tiene como efecto que en la práctica se produzca una coexistencia entre relaciones verticales formales e informales. Mientras priman las de tipo formal entre primero y tercer nivel de gobierno, priman las informales entre segundo y tercero.

\subsection{Normas y ámbitos entre Gobiernos Municipales.}

Pese a su reciente creación, existen también algunos ámbitos incipientes de relacionamiento intermunicipal, particularmente se debe descartar el Plenario de Municipios que ha venido avanzando en la construcción de una agenda conjunta entre los gobiernos locales.

- $\quad$ Plenario de Municipios

Así como el Congreso de Intendentes representa la institucionalidad más relevante de cooperación entre los Intendentes Departamentales, el Plenario de Municipios es la institucionalidad que nuclea a todos los Alcaldes de los Municipios. El Plenario se crea a partir de una iniciativa de los Alcaldes e Intendentes, y es representada por una Mesa Ejecutiva pluripartidaria integrada por nueve alcaldes elegidos en plenaria. Los objetivos primarios del Plenario son muy generales, buscando ser un ámbito que permita compartir buenas prácticas e identificar posibles alianzas, entre otros asuntos que busquen fortalecer el tercer nivel de gobierno.

Sin embargo, es un espacio de reciente formación que no pueda tomar resoluciones formales sobre la gestión de los municipios, y menos incidir de manera directa sobre los otros niveles de gobierno. De hecho, este espacio se formaliza por medio de una resolución del Congreso de Intendentes del 4 de julio de 2013, dando cuenta de la dependencia hacia el nivel superior de gobierno.

- $\quad$ Redes de municipios y acuerdos intermunicipales

Más allá del Plenario de Municipios que, pese a las debilidades, ha sido el espacio de mayor coordinación intermunicipal, se han empezado a crear de forma incipiente algunos 
espacios y acuerdos sobre asuntos concretos que promueven la coordinación entre municipios con temáticas comunes. Ejemplo de esto es la Red de Municipios Turísticos, que funciona a partir de una iniciativa de la Comisión de Turismo del Plenario de Municipios, y que viene funcionado de manera regular, compartiendo experiencias y realizando cursos de capacitación con el apoyo de otras instituciones como el Ministerio de Turismo y Deportes, y el Congreso de Intendentes.

\section{DISCUSIÓN: ENTRE LA LÓGICA FORMAL E INFORMAL DE LAS RIGS EN URUGUAY.}

Hasta aquí se han presentado sucintamente los principales ámbitos y/o reglas formales que regulan el relacionamiento intergubernamental multinivel en Uruguay. Estas lógicas formalizadas conviven en la práctica con modalidades de RIGs denominadas informales, mayormente dependientes de los lazos partidarios e ideológicos. También coexisten con otras que tienen que ver con lo que Jordana denomina "redes profesionales" mayormente dependientes de los contactos y vínculos personales existentes entre técnicos y funcionarios de los distintos niveles de gobierno. La modalidad que asuman dichas lógicas informales, y su interacción con las lógicas formales, determinarán distintos escenarios sobre los niveles de descentralización, autonomía y fortalecimiento de los gobiernos subnacionales.

Si se atiende al funcionamiento de los ámbitos formales establecidos, tales como la CSD o el Congreso de Intendentes, se advierte una fuerte politización que puede dar lugar a la primacía de una lógica partidaria de relacionamiento intergubernamental por sobre otra de tipo formalista. La propia composición de la CSD así lo determina. Los intendentes delegados del Congreso de Intendentes en la CSD, suelen ser actores políticos de primera línea en sus respectivos partidos. En estos espacios, cada partido cuenta con delegados partidarios que asesoran y son quienes negocian con las distintas bancadas del congreso, y además son quienes conectan con el Plenario de Municipios y con los delegados partidarios de éste, favoreciendo un accionar congruente en clave partidaria.

A su vez, los principales partidos coinciden en que son fuertemente institucionalizados y centralizados desde el punto de vista organizacional, con estructuras políticas fuertemente dependientes de las cúpulas de fracción. En este sentido, el relacionamiento intergubernamental informal partidario se encuentra promovido por las reglas electorales que generan un predominio de los niveles territoriales superiores sobre los inferiores a nivel de la organización de los propios partidos políticos. En la elección del Parlamento, la lista a diputados esté en la misma hoja de votación que la lista al senado, por lo que hay una clara subordinación del orden territorial (diputados) sobre la lógica nacional (senado). Mientras que a nivel de las elecciones subnacionales, si bien están separadas de las nacionales, no habilitan el voto cruzado entre partidos al momento de elegir Intendente y Concejales, lo que genera un efecto arrastre de la elección departamental sobre la municipal, en detrimento de los liderazgos locales.

Por su parte, a nivel de redes de gobiernos subnacionales o comunidades profesionales que favorezcan la coordinación intergubernamental se ha estudiado muy poco en Uruguay. Sin embargo, es factible que la generación de algunos proyectos de cooperación, como la reciente creación del Plenario Nacional de Municipios genere oportunidades en tal sentido. La posibilidad real que tengan estas redes de sobreponerse a las lógicas político-partidarias, 
demarcará en qué medida podrán convertirse en espacios de coordinación o, por el contrario, serán objeto de cooptación de los niveles superiores.

La interrogante está en cuál es el marco para el desarrollo de las RIGs, independientemente del marco político resultante del proceso electoral, y en este sentido se presentan dos escenarios de mediano plazo claramente diferenciados.

El primer escenario supone profundizar y mejorar las instancias formalizadas de las RIGs, que entre otras cosas, implica la actualización normativa relativa al segundo nivel de gobierno (que data de 1935) así como la referente estrictamente a municipios. En este ámbito, además, resulta necesaria la discusión sobre la posición de los municipios en la estructura orgánica del Estado. Naturalmente, un grado final de lo que podríamos llamar autonomía municipal, estaría relacionado con una descentralización jurídica definitiva y un consecuente otorgamiento de personería jurídica.

Asimismo, resultaría importante tender a robustecer los ámbitos formales como la CSD, dotándola de mayor capacidad técnica y administrativa. En relación a la dimensión fiscal, formalizar el sistema de financiamiento de los municipios, principalmente en lo concerniente a las partidas presupuestales con origen en el Gobierno Departamental, para evitar que prime la discrecionalidad de los Intendentes por sobre un criterio de equilibrio o cohesión territorial. En cuanto a la dimensión política, avanzar en la desvinculación de la elección municipal de la departamental a través de reformas electorales que por ejemplo posibiliten el voto cruzado entre ambos niveles. Este primer escenario podría configurar una relación estable en lo político y tendiente a un mayor equilibrio desde el punto de vista de la distribución de los recursos en el territorio.

Un segundo escenario estaría pautado por el desarrollo de una dinámica mayormente informal de las RIGs. La ideología y la influencia de las élites locales sobre los partidos políticos se consolidarían como los móviles de las RIGs informales a través de los partidos (Jordana 2001). Estos mecanismos informales tienden a variar en función del contexto político y de la propia característica de los líderes políticos, por tanto, no aseguran como lo harían los mecanismos formales, una estabilidad o un equilibrio en el relacionamiento intergubernamental. Se profundizaría la lógica político-partidaria en el funcionamiento y toma de decisiones de los ámbitos formalmente establecidos. Se debilitarían los ámbitos de discusión distributivos y primarían las estrategias de acumulación partidaria en un contexto de mayor centralización e imponiendo la escala nacional sobre la territorial.

Ambos escenarios operan como límites de un marco de reformas que aparecen en el mediano plazo y de su resolución dependerá en parte el éxito del proceso descentralizador del Uruguay.

\section{BIBLIOGRAFÍA CONSULTADA.}

AGENDA METROPOLITANA. (2007). Libro blanco del Área Metropolitana. Uruguay: Editorial Agenda Metropolitana.

CARRIÓN, Fernando. "La descentralización: una perspectiva comparada entre América Latina y Europa". Quórum: Revista de pensamiento Iberoamericano, 2004, pp. 19-33.

CHASQUETTI, Daniel. Democracia, presidencialismo y partidos políticos en América Latina: Evaluando la "difícil combinación, 2008, Montevideo: Ediciones CAUCE. 
DELPIAZZO, Carlos. "Derecho Administrativo Especial. Volumen 1". Montevideo. Ed. AMF, 2209 , pp.149 - 154

FALLETI, Tulia. "A Sequential Theory of Decentralization: Latin American Cases in Comparative Perspective". American Political Science Review, 2005 pp. 327-346.

FARIÑA, Fermín y OVIEDO, María José. "Algunas modificaciones introducidas por el presupuesto nacional a través de la Ley $\mathrm{N}^{\circ} 19.355$ al régimen de los municipios (Ley 19.272)”. Revista de Derecho Público - Año 26 - Número 51 - Julio 2017 - pp. 191-196.

FREIGEDO, Martín y RODRÍGUEZ, José Raúl. "Las capacidades estatales de los Gobiernos Departamentales en Uruguay". 2019, Mimeo.

FREIGEDO, Martín.; ABRAHAN, Manuela.; MILANESI, Alejandro. "Reyes que no reinan: los avances a nivel municipal en el gobierno de Mujica". En: Bentancur, Nicolás; Busquets, José. (Eds.). El decenio progresista. Las políticas públicas, de Vázquez a Mujica. Montevideo: ICP, 2016, pp. 351-373.

FREIGEDO, Martín. "Las capacidades institucionales en el marco de la descentralización fiscal de los gobiernos subnacionales en Uruguay. Un análisis de tres gobiernos frenteamplistas." Tesis de Maestría, Univ. Autónoma Metropolitana, 2012, México.

GUEDES, Alejandro. "Éxito presidencial y concesiones legislativas. Uruguay", 2000-2009. Revista Uruguaya de Ciencia Política, 2017, pp. 151-174.

JORDANA, Jacint. "Equilibrios institucionales y mecanismos de coordinación”. En Relaciones intergubernamentales em América Latina: uma perspectiva institucional. Documento de trabajo. Proyecto conjunto INDES-Unión Europea. Serie de Documentos de Trabajo I-22 UE. BID. Washington DC, 2001, pp. 25-59.

MAGRI, Altair.; FREIGEDO, Martín y TEJERA, Rafael. Construyendo gobernanza: presente y desafíos para el Área Metropolitana de Montevideo. Montevideo, 2011: UdelaR, FCS, CIP, CSIC.

MONTECINOS, Egon. Los estudios de descentralización en América Latina: una revisión sobre el estado actual de la temática. EURE (Santiago), 2005, pp. 73-88.

RODRÍGUEZ PINHO, José Raúl "Capacidades estatales para las políticas públicas en las intendencias de Uruguay (1995-2015)". Ponencia presentada en el V Congreso Uruguayo de Ciencia Política. AUCiP, 2014. Mimeo. Montevideo.

VÁZQUEZ, Cristina "Los acuerdos de los Gobiernos Departamentales. El Congreso de Intendentes" en Reforma Constitucional de 1997, Universidad Católica del Uruguay, Serie de Congresos y Conferencias $\mathrm{N}^{\circ} 16$.

Fecha de recepción: 12 de setiembre 2019.

Fecha de aceptación: 28 octubre 2019. 
